\title{
Acquired arterial macroaneurysms of the retina
}

\author{
RICHARD ALAN LEWIS, EDWARD W. D. NORTON, AND J. DONALD M. GASS \\ From the Bascom Palmer Eye Institute, Department of Ophthalmology, \\ University of Miami School of Medicine, Miami, Florida
}

Isolated aneurysms of the four principal divisions of the central retinal artery are found infrequently in older individuals. Robertson (1973) suggested the designation 'macroaneurysm' to distinguish these dilatations of the major arterial branches from the microaneurysms of the retinal capillaryvenous plexus. These acquired macroaneurysms are usually unilateral and may be associated with intraretinal oedema, blood, and exudates, subretinal blood and exudation, and rarely, intravitreal haemorrhage which may obscure the aneurysm. Their genesis has been ascribed to hypertension (Robertson, 1973), arteriosclerosis (Robertson, 1973; Ballantyne, I937), ageing (Shults and Swan, 1974), and various degenerative conditions (Doyne, I896; Raehlmann, I902; Ashton and Langley, I95 I).

The clinical and fluorescein angiographic findings in 15 cases of acquired arterial macroaneurysms of the retina and our experience with management (Table) are summarized in this report. The findings in an adult woman with an unusual profusion of arterial aneurysms who may represent a variation of this phenomenon are presented separately. Other known causes of aneurysmal dilatation such as Leber's multiple miliary aneurysms (Archer and Krill, 197I) or Coats's syndrome (Egerer, Tasman, and Tomer, 1974), and cavernous haemangioma of the retina (Lewis, Cohen, and Wise, 1975) are excluded from this review.

\section{Case report}

CASE I

A 67-year-old white woman stated that, 2 months before her examination at the Bascom Palmer Eye Institute, she had noted an abrupt and persistent diminution of vision in the right eye associated with 'little fine circles of light'. The left eye was amblyopic because of strabismus in childhood. Although she was unaware of a

This study was supported in part by US Public Health Service Grant EY- -00338

Address for reprints: Richard Alan Lewis, MD, B-2964 Clinical Faculty Office Building, Department of Ophthalmology, University of Michigan Medical Center, 1405 East Ann Street, Ann Artor, Michigan, 48109, USA history of hypertension or diabetes mellitus, she had experienced transient ischaemic episodes for many years.

The corrected visual acuity was $20 / 50$ in the right eye and $20 / 100$ in the left, which showed anomalous retinal correspondence. Intraocular pressure was $22 \mathrm{~mm} \mathrm{Hg}$ in the right eye and $26 \mathrm{~mm} \mathrm{Hg}$ in the left. Biomicroscopy showed subepithelial nodular and whorl-like opacities in each cornea.

Ophthalmoscopy of the right eye revealed a localized intraretinal haemorrhage along a branch of the inferior temporal artery distal to its fourth bifurcation (Fig. I $a$ ). A yellowish-white plug was visible within the artery at that point and appeared to move to and fro synchronously with the carotid pulse. The lumen of the artery proximal to the plug was narrow and markedly irregular. Surrounding the obstruction and haemorrhage was an incomplete ring of circinate deposits. Mild intraretinal oedema extended into the foveal area and there was a delicate hemimacular star temporally. The retina distal to the haemorrhage was otherwise normal. No additional evidence of arterial embolization was found but the calibre of other arteries was irregular, and tapering and deflexion of many arterio-venous crossings were evident. The optic disc had a normal hyperopic configuration and the visual field was normal.

The vessels of the left fundus showed similar hypertensive changes. The left optic disc was irregularly raised suggesting drusen formation, and a sector defect was demonstrated on visual field examination.

Fluorescein angiography demonstrated normal transit of dye to the site of the plug in the right eye but marked delay of filling of the artery distally until the midvenous phase (Fig. $\mathrm{x} b$ ). No retrograde flow in the artery was demonstrated but late in the study the vessel wall stained intensely at the point of obstruction.

The patient's right brachial artery blood pressure was $180 / 100 \mathrm{~mm} \mathrm{Hg}$. Ophthalmodynamometry was normal and similar in each eye.

\section{Course}

The patient was started on antihypertensive medications. Six weeks later the haemorrhage had cleared and an aneurysmal dilatation of the artery was present at the site of the previous obstruction. Ten weeks after initial examination the visual acuity in the right eye had improved to $20 / 30$. Fluorescein angiography showed that the aneurysm was bilobed, that there was no delay in the perfusion of the aneurysm or distal artery, that there was an avascular halo around the aneurysm, and 


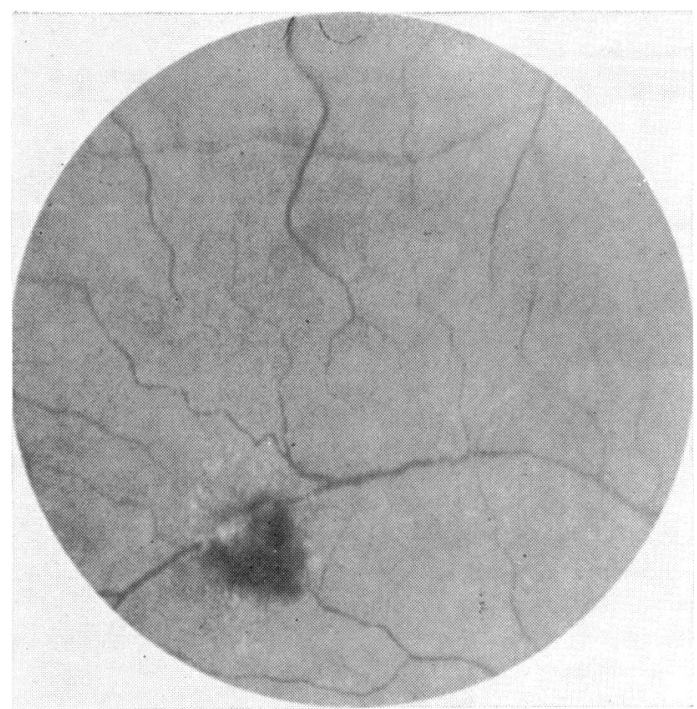

(га)

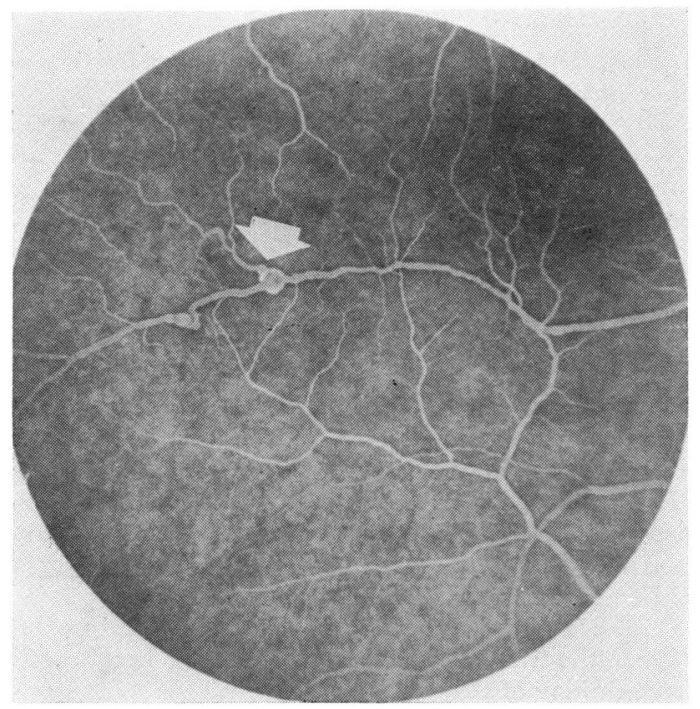

( $\mathrm{d}$ d)

that the adjacent capillaries were slightly dilated (Fig. Ic).

One year after presentation, a new fusiform aneurysm had developed at the next more proximal bifurcation of the artery to the original macroaneurysm, in an area which had not been involved by the plug either ophthalmoscopically or angiographically.

Four years and 3 months after the initial examination the visual acuity in the right eye was $20 / 50$. The original aneurysm was still patent and the aneurysm at the bifurcation had expanded to about five times the width of the vessel and had developed a small satellite along the smaller branch of the bifurcation (Fig. I $d$ ).

One year later, although the visual acuity was unchanged, there was an increase in intraretinal exudate and oedema surrounding the large aneurysm at the bifurca-

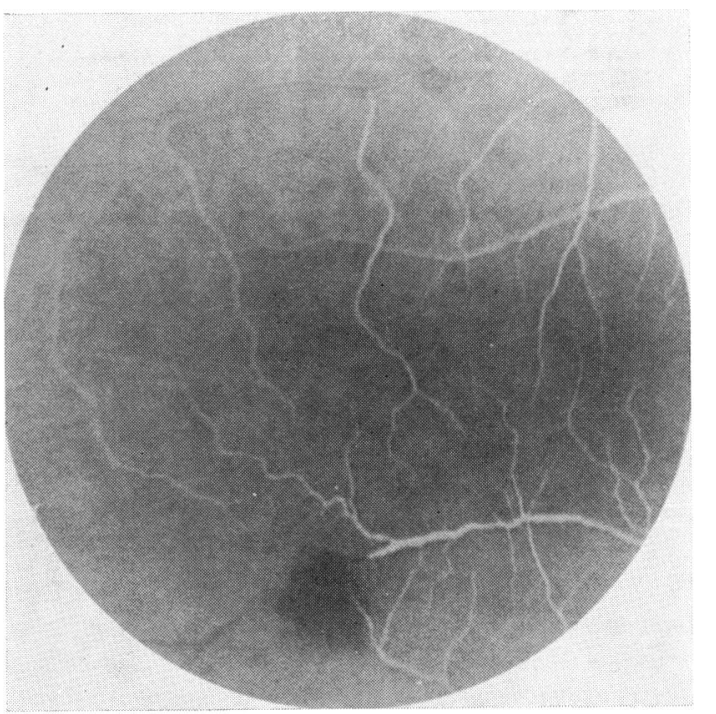

( $\mathrm{rb})$

FIG. I

a Case I. Haemorrhage partially obscures distal inferior temporal artery of right eye at site of intraluminal plaque

b Case I. Fluorescein angiography on same day shows delayed perfusion beyond intravascular material. Subsequently, antegrade filling of artery ensued but arterial wall stained at site of obstruction

c Case I. Ten weeks later, angiography showed bilobed macroaneurysm at former site of plaque. No delayed perfusion or dye leakage seen. Note irregular calibre of feeding artery

d Case I. More than 4 years later, original aneurysm remains patent and new macroaneurysm at arterial bifurcation has enlarged and formed small satellite (arrow)

e Case I. One year later, aneurysm at bifurcation has enlarged further. Dot haemorrhages scattered near macroaneurysm and another fusiform enlargement of artery appears proximal to arterio-venous crossing (arrow)

tion. Fluorescein angiography demonstrated delayed flow into the smaller branch of the involved bifurcation, staining of the wall of the larger aneurysm and of the small branch artery, and late leakage into the oedematous retina from each area (Fig. $r e$ ). The patient died one month later of a combined cerebrovascular accident and myocardial infarction.

\section{Comment}

The evolution and possible aetiology of the arterial macroaneurysms are documented in this hypertensive woman with intracranial vascular symptoms. The process began as an incomplete occlusion of a branch retinal artery; additional aneurysms developed in this damaged 


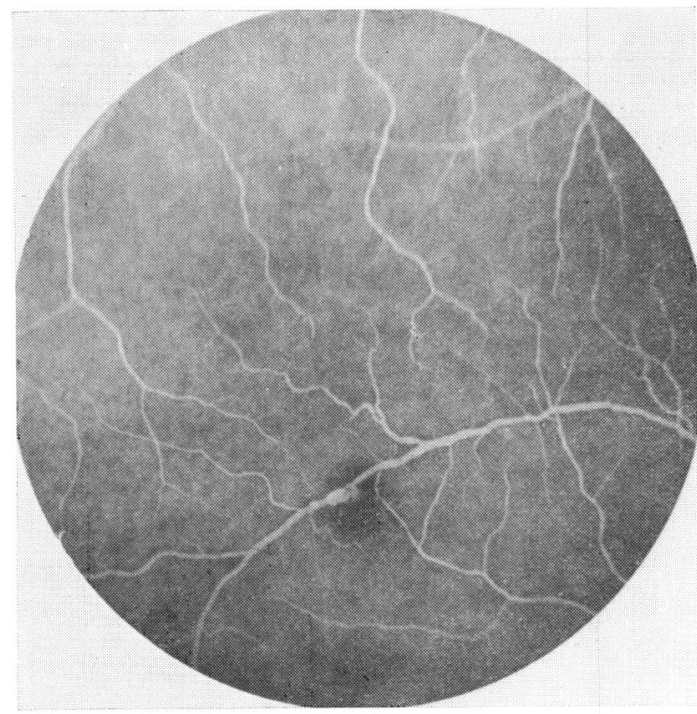

(Ic)

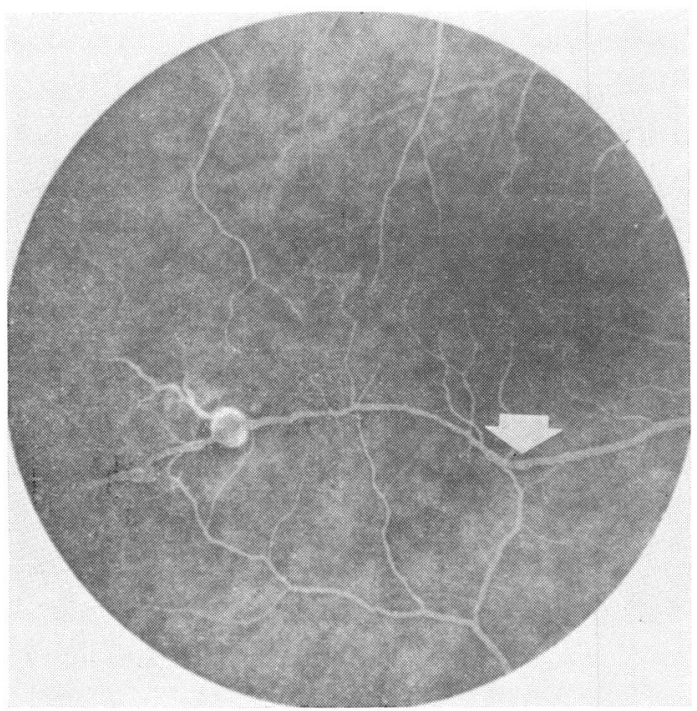

(re)

vessel. The occlusion was attributed to embolic material although the possibility of local vascular disease as a predisposing factor cannot be excluded. The attenuated irregular lumen of the artery proximal to the obstruction and the permeability of its wall to fluorescein suggest damage to the vessel as the obstructing element travelled through it. The absence of visual field defect in the right eye is possibly explained by the incomplete closure of the artery which permitted perfusion of the retina sufficient to prevent ischaemic infarction.

\section{CASE 5}

A 49-year-old white woman had sudden blurring of vision in the right eye. Her ophthalmologist observed a haemorrhage overlying an abnormal vessel in the right fundus and an anomalous loop of blood vessels associated with a localized area of exudate in the left eye. The patient was admitted to hospital for extensive investigation, including haematological and serological studies, liver function studies, glucose tolerance test, intravenous pyelography, electrocardiography and skull $x$ rays. The only abnormality was labile systemic hypertension, with a diastolic blood pressure ranging between 90 and $100 \mathrm{~mm} \mathrm{Hg}$. The past medical history was unremarkable.

\section{Ocular evaluation}

Three months after the onset of symptoms, the visual acuity was $20 / 40$ in the right eye and $20 / 20$ in the left.

Ophthalmoscopy of the right eye identified a macroaneurysm along a small loop in the inferior temporal artery distal to its first bifurcation. The lesion was covered by superficial intraretinal haemorrhage and was surrounded by a broad zone of oedema and a dense ring of exudate which extended into the macula. A bright white plaque was located in the artery just proximal to the aneurysm (Fig. 2a). A widened and copper-wire light reflex was evident in most arteries in the fundus and the major arterio-venous crossings showed deflexion and concealment of the venous blood column.

In the left eye a large aneurysm was located at the fourth bifurcation of the superior temporal artery (Fig. $2 b$ ) and was surrounded by a small zone of retinal oedema and circinate material. A burnished light reflex, irregularities of arterial calibre, and banking and compression of arterio-venous crossings were present throughout the fundus.

Fluorescein angiography of the right eye showed prompt and complete perfusion of the aneurysm and the entire retinal vasculature. The capillary-free zone around the aneurysm was widened and the adjacent microvasculature was moderately altered (Fig. 2c). Corresponding to the intraluminal plaque was a defect in the fluorescein column in the artery. The wall of the aneurysm stained with dye and subsequently leaked into the adjacent retina. Angiography of the left eye also demonstrated no evidence of arterial obstruction but some leakage of dye from the walls of the aneurysm.

\section{Course}

The patient was started on antihypertensive medications. Although the brachial artery blood pressure became normal during the next 2 months (140/76 $\mathrm{mm} \mathrm{Hg}$ ), the visual acuity of the right eye gradually deteriorated to $20 / 100$ with increased circinate material in the macula. The walls of the aneurysm became thickened and grey, and the intra-arterial plaque remained. The arterial segment distal to the aneurysm thinned to about onethird of its original diameter and its blood column was segmented and venous in colour. Fluorescein angiography dramatically displayed obstruction of arterial perfusion and retrograde filling of the distal artery from branch venous channels (Fig. $2 d$ ). The lesion in the left eye was unchanged. Visual field examination of the right eye showed a superior altitudinal depression within which was a dense scotoma corresponding with 
Table Summary of cases with acquired retinal arterial macroaneurysms

\begin{tabular}{|c|c|c|c|c|c|c|c|c|}
\hline Case & $\begin{array}{l}\text { Age } \\
(y r)\end{array}$ & Sex & Race & Eye & $\begin{array}{l}\text { Visual } \\
\text { acuity } \\
\text { at onset }\end{array}$ & $\begin{array}{l}\text { Treat- } \\
\text { ment* }\end{array}$ & Medical history & Final visual acuity \\
\hline $\mathbf{I}$ & 67 & Female & White & Right & $20 / 50$ & - & $\begin{array}{l}\text { History of transient } \\
\text { ischaemic attacks for years } \\
\text { Hypertension discovered at } \\
\text { onset }\end{array}$ & $\begin{array}{l}20 / 50(52 / 12 \mathrm{yr}) \\
\text { Died of combined } \\
\text { myocardial infarction } \\
\text { and stroke }\end{array}$ \\
\hline 2 & 64 & Female & Black & Right & $20 / 25$ & 一 & $\begin{array}{l}\text { Severe uncontrolled hyper- } \\
\text { tension for years } \\
\text { Goitre, parathyroid adenoma, } \\
\text { sarcoidosis }\end{array}$ & $\begin{array}{l}\text { Lost to follow-up } \\
\text { Died } 4 \text { yr later of stroke }\end{array}$ \\
\hline 3 & $5^{8}$ & Male & White & Left & $20 / 25$ & -- & $\begin{array}{l}\text { 30-year history of hyper- } \\
\text { tension } \\
\text { Chemical diabetes for I year }\end{array}$ & $20 / 30(25 / 12 \mathrm{yr})$ \\
\hline 4 & 73 & Female & White & Right & $\begin{array}{l}\mathrm{CF} \\
\mathrm{I} \cdot 5 \mathrm{~m}\end{array}$ & A & $\begin{array}{l}\text { Poorly controlled hyper- } \\
\text { tension for decades }\end{array}$ & $\begin{array}{l}20 / 200(3 \mathrm{yr} \text { after } \\
\text { treatment })\end{array}$ \\
\hline 5 & 49 & Female & White & $\begin{array}{l}\text { Right } \\
\text { Left }\end{array}$ & $\begin{array}{l}20 / 40 \\
20 / 15\end{array}$ & - & $\begin{array}{l}\text { Hypertension discovered } \\
\text { at onset }\end{array}$ & $\begin{array}{l}20 / 25(22 / 12 \text { yr after } \\
\text { treatment) } \\
20 / 15 \text { (no change, } 2 \frac{1}{2} \mathrm{yr} \text { ) }\end{array}$ \\
\hline 6 & 60 & Male & White & Right & $20 / 400$ & $\mathrm{X}$ & $\begin{array}{l}\text { Normotensive } \\
\text { Negative glucose tolerance } \\
\text { test }\end{array}$ & $\begin{array}{l}6 / 200(3 \mathrm{yr} \text { after } \\
\text { treatment })\end{array}$ \\
\hline 7 & 69 & Female & White & Right & $20 / 300$ & $\mathrm{X}$ & $\begin{array}{l}\text { Hypertension for I } 3 \text { years } \\
\text { Angina pectoris for 10 years }\end{array}$ & $\begin{array}{l}20 / 40(5 \mathrm{yr} \text { after } \\
\text { treatment) }\end{array}$ \\
\hline 8 & 62 & Male & Black & Right & $20 / 302$ & $\mathrm{X}$ & $\begin{array}{l}\text { Hypertension discovered at } \\
\text { onset }\end{array}$ & $\begin{array}{l}20 / 30(2 \mathrm{IO} / \mathrm{I} 2 \mathrm{yr} \text { after } \\
\text { treatment) }\end{array}$ \\
\hline 9 & $5 \mathrm{I}$ & Male & White & Right & $20 / 200$ & A & $\begin{array}{l}\text { Diastolic hypertension at } \\
\text { onset }\end{array}$ & $\begin{array}{l}20 / 50(3 \mathrm{yr} \text { after } \\
\text { treatment })\end{array}$ \\
\hline 10 & 71 & Female & White & Left & $20 / 40$ & - & $\begin{array}{l}\text { Hypertension discovered at } \\
\text { onset } \\
\text { 3-year history of bilateral } \\
\text { vitritis, uveitis, and } \\
\text { cystoid macular oedema }\end{array}$ & $20 / 40(2 \mathrm{yr})$ \\
\hline I I & 82 & Male & White & Left & $\begin{array}{l}\mathrm{CF} \\
2 \cdot 7 \mathrm{~m}\end{array}$ & $\mathrm{X}$ & $\begin{array}{l}\text { Mild hypertension at onset } \\
\text { Adult diabetes mellitus for } \\
25 \text { years }\end{array}$ & $\begin{array}{l}\text { 20/100 (lost to follow-up } \\
2 / 12 \text { yr after } \\
\text { treatment) }\end{array}$ \\
\hline 12 & 71 & Female & White & Right & $20 / 200$ & $\mathrm{X}$ & $\begin{array}{l}\text { Hypertension poorly con- } \\
\text { trolled for } 12 \text { years }\end{array}$ & $\begin{array}{l}20 / 30 \text { ( } 1 \text { yr after } \\
\text { treatment) } \\
\text { Died after abdominal } \\
\text { aortic aneurysm }\end{array}$ \\
\hline I 3 & 59 & Female & White & Right & $20 / 200$ & A & $\begin{array}{l}\text { Hypertension } \\
\text { Adult diabetes mellitus for } \\
\quad \text { I year }\end{array}$ & $\begin{array}{l}20 / 200(5 / 12 \text { yr after } \\
\text { treatment) } \\
\text { Died of combined myo- } \\
\text { cardial infarction and } \\
\text { stroke }\end{array}$ \\
\hline 14 & 71 & Female & White & Right & $20 / 200$ & 一 & $\begin{array}{l}\text { Hypertension poorly con- } \\
\text { trolled for I } 3 \text { years } \\
\text { Hypercholesterolaemia }\end{array}$ & $20 / 40\left(\mathrm{I} \frac{1}{2} \mathrm{yr}\right)$ \\
\hline I 5 & 83 & Male & White & Right & $20 / 40$ & $\mathrm{~A}$ & $\begin{array}{l}\text { Hypertension discovered at } \\
\text { onset } \\
\text { Spastic paraplegia after } \\
\text { septic meningitis as youth }\end{array}$ & $\begin{array}{l}20 / 25(4 / 12 \text { yr after } \\
\text { treatment })\end{array}$ \\
\hline 16 & 69 & Female & White & Right & $20 / 30$ & 一 & $\begin{array}{l}\text { Angina pectoris for ro } \\
\text { years }\end{array}$ & $20 / 40$ (I $3 / 12$ year) \\
\hline
\end{tabular}

*A = Argon photocoagulation $\mathrm{X}=$ Xenon photocoagulation $-=$ No treatment 


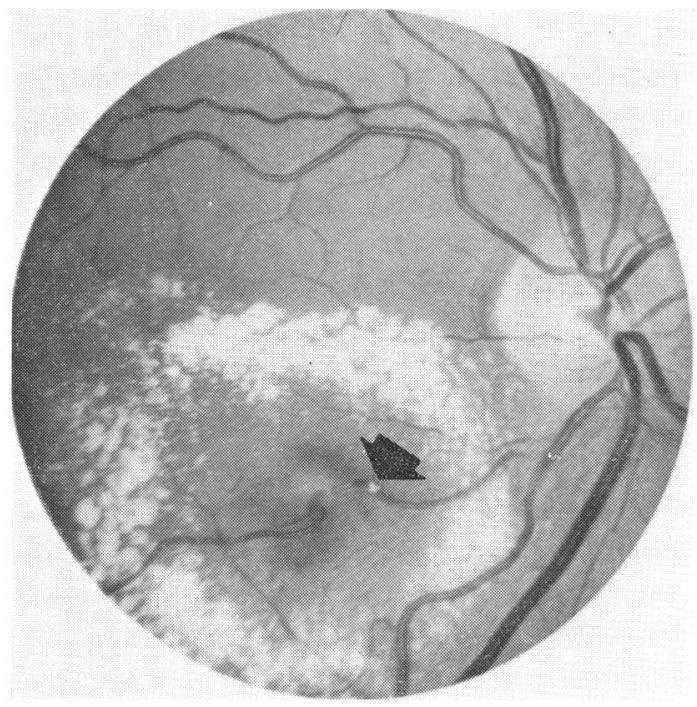

(2a)

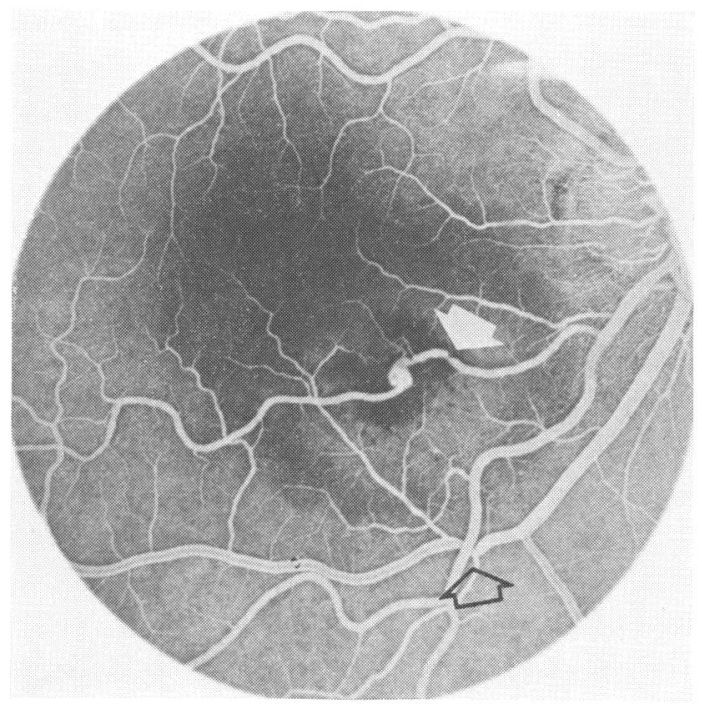

(2c)

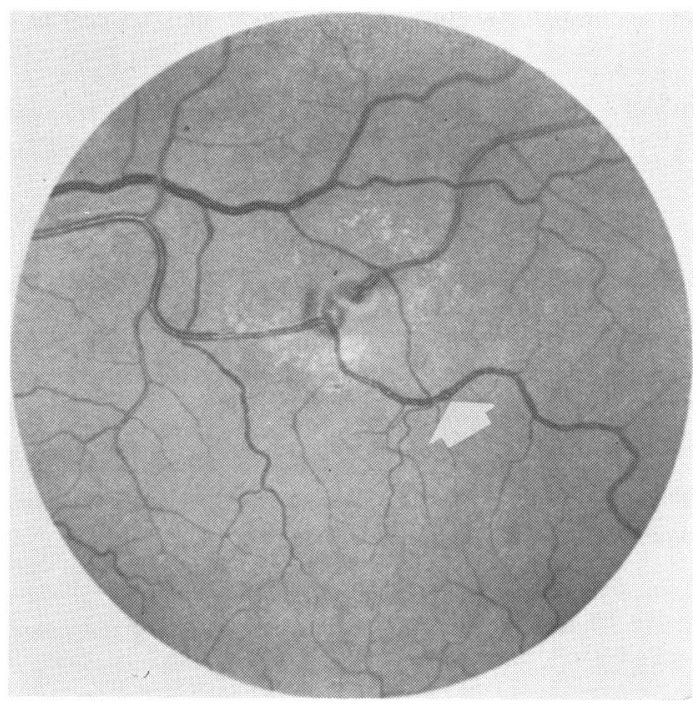

(2b)

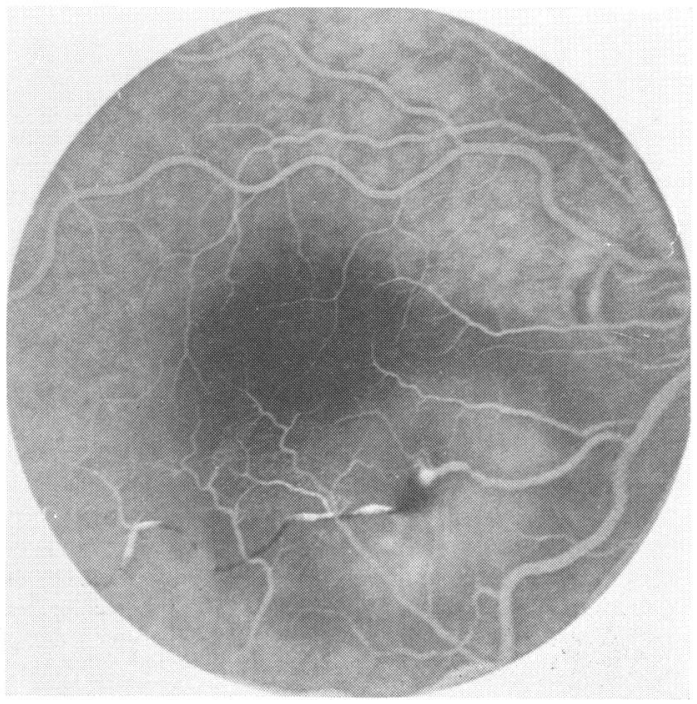

(2d)

FIG. 2 a Case 5. Macroaneurysm of inferior temporal artery of right eye surrounded by macular oedema and dense circinate ring. Bright white plaque located in artery proximal to macroaneurysm (arrow)

b Case 5. Horse-shoe shaped macroaneurysm of superior temporal artery of left eye is associated with small zone of retinal oedema and exudates. Note small fusiform enlargement of adjacent branch artery (arrow)

c Case 5. Midvenous phase of fluorescein angiogram of right eye. Note defect in fuorescein column corresponding to bright plaque in Fig. 2a (white arrow). Disruption of laminar venous flow is present at arterio-venous crossing (open arrow)

$\mathrm{d}$ Case 5. Two months later, late venous angiogram shows obstruction of arterial perfusion at macroaneurysm and segmental retrograde filling of distal artery from venous tree. Macular oedema is more extensive

the aneurysm, and in the left eye a relative scotoma corresponding with that aneurysm. Because of the failing central vision in the right eye, 68 applications ( $100 \mu \mathrm{m}$ spot size, $0.1 \mathrm{~s}$ duration, $\mathrm{r}_{50-}-300 \mathrm{~mW}$ ) of argon laser photocoagulation were applied to the aneurysm and to the area surrounding it. Seven weeks after treatment the visual acuity was $20 / 25$ in the right eye, the aneurysm had disappeared, and oedema and fatty deposits had begun to resorb, but 26 months after photocoagulation the visual acuity was unchanged. Nearly all the circinate 
material in the right fundus had cleared, leaving a patchy area of depigmentation in the macula. Hypopigmented scars and grey sheathing of the attenuated artery indicated the site of therapy. Apart from minor changes in the pattern of the circinate ring, the aneurysm of the left eye was unaltered.

\section{Comment}

The retinal vasculature in both eyes of this woman showed evidence of long-standing systemic hypertension. Proximal to the arterial macroaneurysms in the right eye was an intraluminal plaque. Although no additional fragment or embolus was seen at the site of the vascular anomaly, the aneurysm was well established at the time of our examination. Whether the existing plaque or factors within the aneurysm or the arterial wall precipitated the arterial occlusion is a matter for conjecture. Photocoagulation promptly eliminated the aneurysm as the source of intraretinal oedema and central visual acuity improved. The macroaneurysm in the left eye was followed for $2 \frac{1}{2}$ years with no important changes or effects upon vision.

\section{CASE 9}

A 5 I-year-old white man had a corrected visual acuity of $20 / 20$ in each eye several months before he experienced the abrupt onset of a grey central scotoma in the right eye. About 3 weeks later, the visual acuity was $20 / 200$ in the right eye and $20 / 20$ in the left.

Temporal to the macula of the right eye a macroaneurysm was situated at the fifth bifurcation of the inferior temporal artery. Distal to the aneurysm, the blood in the branch artery appeared desaturated. The aneurysm was surrounded by a broad zone of thickened oedematous retina extending into the fovea and there were patches of yellow exudates in an incomplete ring pattern temporal and inferior to the aneurysm. The retinal arterial tree demonstrated an increased light reflex, moderate arterial tortuosity, irregular calibre, and arterio-venous compression. In the periphery at the 9 and 12 o'clock meridians were numerous sheathed vessels and intraretinal vascular changes suggestive of old branch retinal vein occlusions.

The vessels of the left fundus were normal except for a copper-wire arterial light reflex and mild arteriovenous crossing defects.

Fluorescein angiography revealed two slight fusiform enlargements of the feeding artery and delay of flow at the site of the macroaneurysm (Fig. 3a). Although the dye eventually perfused the arterial segment distal to the aneurysm, it halted again at the next major bifurcation (Fig. $3 b$ ). Both the aneurysm and the considerable local intraretinal angiopathy leaked dye in the later phases of angiography.

\section{Course}

The patient's brachial artery blood pressure was $150 / 95 \mathrm{~mm} \mathrm{Hg}$. Ophthalmodynamometry was normal and the same in each eye. Altogether $5^{8}$ applications of argon laser photocoagulation (100 $\mu \mathrm{m}$ spot, $0.2 \mathrm{~s}$ dura-

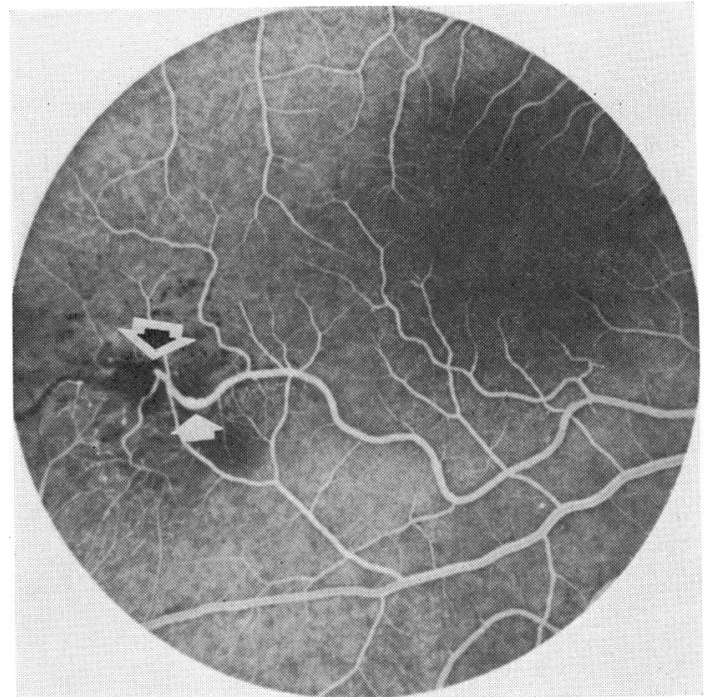

(3a)

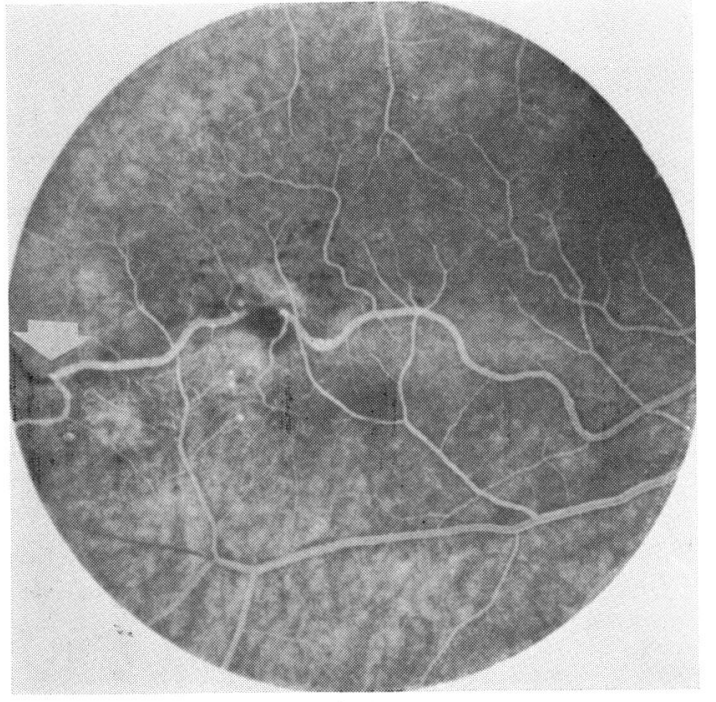

(3b)

FIG. 3

a Case 9. Fluorescein angiography at midvenous phase showed two fusiform enlargements of feeding artery (white arrow) and impediment of flow at macroaneurysm (striped arrow)

b Case 9. Later in venous phase, an additional segment of artery perfuses, but flow halts at next bifurcation (arrow). Note microangiopathy in adjacent vascular bed

tion, $300 \mathrm{~mW}$ ) were directed at the aneurysm and to local zones of microangiopathy. Two months later the visual acuity in the right eye was $20 / 50$, the aneurysm was obliterated, and the retinal oedema and exudate were much reduced. Angiography showed that the artery distal to the aneurysm was totally occluded. Ten months 
after photocoagulation, however, an arterial-arterial collateral diverted flow around the site of the occluded aneurysmal segment into the distal arterial segment. Three years after therapy the visual acuity was $20 / 50$ and no new lesions had appeared.

\section{Comment}

Although this patient had only borderline diastolic hypertension, there was evidence of hypertensive retinal vascular changes. Fluorescein angiography showed arterial occlusions although no intraluminal emboli were seen clinically. Photocoagulation quickly eliminated the source of macular oedema and improved visual acuity.

\section{CASE 16}

A 69-year-old white woman experienced 'flashing lights' and triangular floaters in her right eye for 2 months before she consulted her ophthalmologist. She stated that the visual acuity in the right eye had never been as clear as that in the left. Although she had had angina pectoris for about ro years, she had no history of hypertension or medical problems other than bilateral mastectomies for fibrocystic disease.

The visual acuity was $20 / 25$ in the right eye $(-0.75$ D sph., $+3.25 \mathrm{D}$ cyl., axis $120^{\circ}$ ) and $20 / 20$ in the left eye $(+\mathrm{I} \cdot 75 \mathrm{D}$ sph.). Ophthalmoscopy of the right fundus showed numerous arterial macroaneurysms involving only the temporal retinal vasculature (Figs $4 a, b$ ). These varied from small fusiform enlargements of the arterial wall to irregular saccular swellings four or five times the diameter of the feeding vessel. None of the lesions was haemorrhagic although several large ones were surrounded by small zones of oedematous retina demonstrated by circinate deposits. One branch of the superior temporal artery with pipestem sheathing and irregular attenuation of its lumen became a ghost vessel more distally, and a resolving cotton-wool patch was noted in its distribution. No delay of perfusion was identified through any of the aneurysms during fluorescein angiography. A cluster of tortuous collateral vessels rimmed one of the larger aneurysms (Fig. $4 c$ ). The left fundus was normal.

The brachial artery blood pressure and the results of ophthalmodynamometry were normal and symmetrical.

Fifteen months later, the corrected visual acuity was $20 / 40$ in the right eye. Central metamorphopsia and a paracentral scotoma were demonstrable in the right eye on an Amsler grid. At least 18 arterial aneurysms were visible on various branches of the temporal vasculature. No abnormalities of the nasal vessels were seen. Several of the aneurysms were well anterior to the equator and surrounded by circinate rings. Several aneurysms in the posterior pole were overlaid with recent haemorrhages. Some of the previously recognized aneurysms had enlarged considerably and others appeared in formerly normal areas (Fig. 4d). Mild cystoid macular oedema was noted. Fluorescein angiography dramatically showed the vascular malformations and mild leakage from multiple macroaneurysms. The left eye was normal. No treatment was instituted.

\section{Comment}

This normotensive woman presents an exceptional number and distribution of arterial aneurysms without vascular anomalies. The condition does not resemble the syndrome of Leber's multiple miliary aneurysms and it may be incorrect to group this patient with the cases of acquired retinal arterial macroaneurysms described above. The findings are not therefore included in this summary. It is not known whether the lesions were solely acquired or influenced by unseen or congenital factors.

\section{Discussion}

Although aneurysms of the major arteries have been recognized in various retinal disorders for many decades (Doyne, I896; Story and Benson, I 883), the designation 'macroaneurysm' was applied recently to a specific acquired lesion by Robertson (1973) in his review of 13 cases. Six other cases have been reported more recently (Hudomel and Imre, I973; Shults and Swan, 1974). The average age at presentation of our patients was 66 years (median 67 ; range 49 to 83 ). Nine of our I 5 patients were female, which confirms the reported prevalence of this condition in females. The relationship of this finding with the recognized predominance of intracranial aneurysms in women after the age of 50 years (Walsh and Hoyt, 1969) is obscure.

Thirteen of our patients either had a history of systemic hypertension or hypertension was discovered at the time of consultation. Three of the 13 also had diabetes mellitus of adult onset although none had clinically significant diabetic retinopathy. The association of severe hypertension with retinal arterial aneurysms appears to have been first reported by Fernandez (1920) in a 54-year-old man who died 40 days after presentation of a cerebral haemorrhage. Robertson (1973) emphasized the coexistence of hypertension with the retinal pathology. More than half of his patients had mild to severe hypertension. He also suggested that the occurrence of macroaneurysms was not necessarily an ominous prognostic sign, since two of his patients survived more than a decade after discovery of the lesion. However, four of our patients died between 9 months and $5 \frac{1}{4}$ years after presentation, one of a stroke, two of combined myocardial infarction and stroke, and one shortly after resection of a symptomatic abdominal aortic aneurysm. While a retinal arterial macroaneurysm per se may not be prognostic of early death, it may herald the discovery of coexisting hypertension or other systemic vascular disease which could affect a patient's life expectancy. At a minimum, therefore, we recommend measurement of the systemic blood pressure during the investigation of patients with this lesion. Ophthalmodynamometry, on the other 


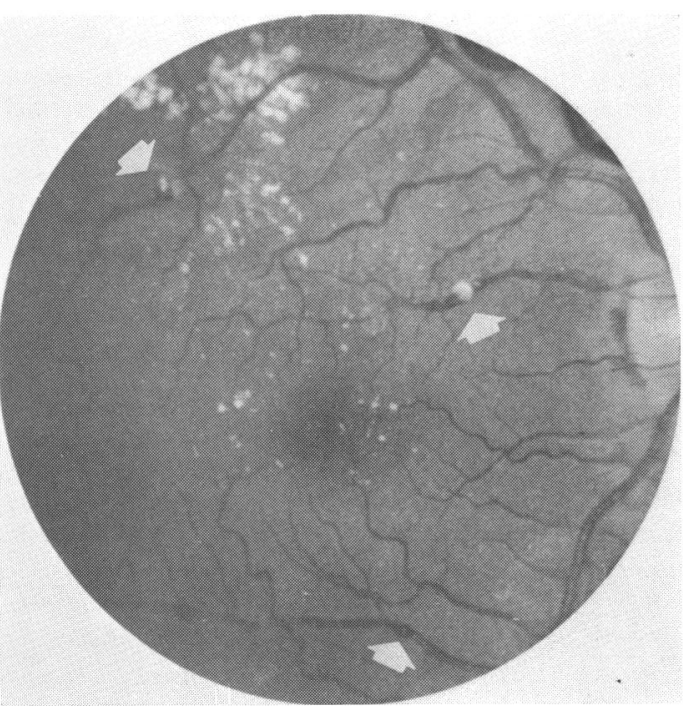

(4a)

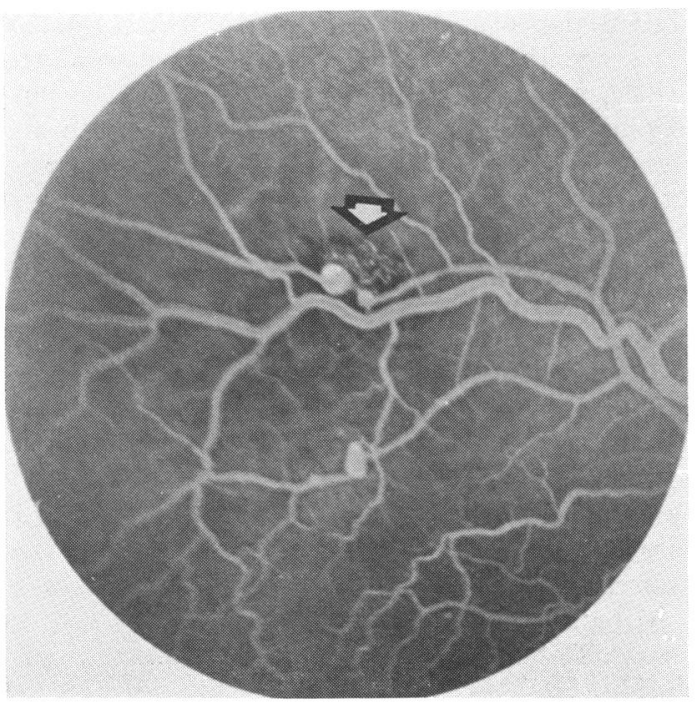

(4c)

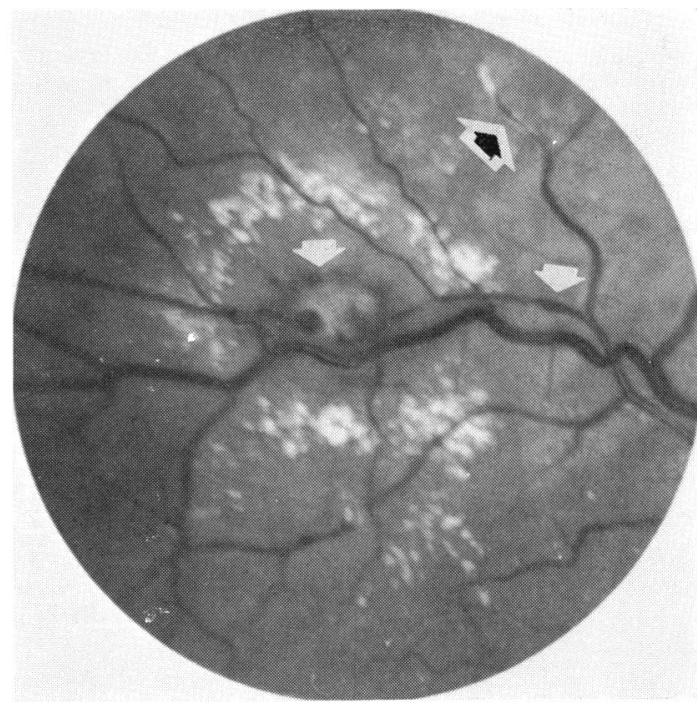

(4b)

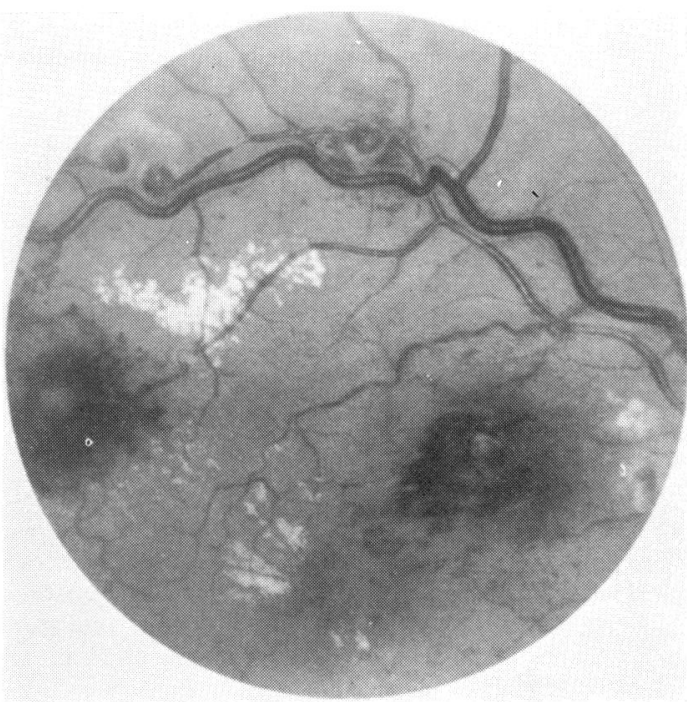

(4d)

FIG. 4 a Case 16 . Several macroaneurysms (arrows) of temporal arteries of right eye with associated exudates

b Case i6. Other macroaneurysms superotemporally (white arrows). One branch artery is sheathed and partially occluded (arrow)

c Case i6. Angiography shous cluster of small tortuous collateral vessels around one of the macroaneurysms (arrow)

$\mathrm{d}$ Case i6. Fifteen months later, several macroaneurysms have enlarged and some are obscured by blood (compare with Fig. $4 \mathrm{a}$ and b)

hand, was not revealing in the patients tested.

One patient (Case 5) had bilateral aneurysms. Among patients affected unilaterally, i I (79 per cent) had the right eye involved. We cannot explain this prevalence, although it follows the trend in other series (Robertson, I973; Shults and Swan, I974). All aneurysms were temporal to the optic disc and in 10 of 16 affected eyes, the lesions were superior to the horizontal raphe, including one patient (Case 6) with two aneurysms on a cilioretinal artery. Macular oedema and circinate retinopathy were no more frequent with superior than with inferior malformations.

Of 17 separate aneurysms in these 16 eyes, seven 
occurred at an arterial bifurcation and three more at a point of arterio-venous crossing, and in each of these there were intraluminal plaques in the same or adjacent branch arteries (Cases 3, 7, 14). Among the other seven aneurysms, four were accompanied by clinical or angiographic evidence of complete or incomplete arterial occlusion and another by a resolved branch retinal vein occlusion elsewhere in the same fundus. Two patients (Cases $5,8)$ had arcuate altitudinal field defects at presentation, suggesting a previous major arterial occlusion at the optic disc.

Various factors have been implicated in the production of arterial aneurysms. Doyne (I896) attributed his findings to a 'plugged beaded vessel'. Robertson (1973) considered ageing, hypertension, and generalized arteriosclerosis to be important considerations. Interestingly, one of his patients was described as having multiple cholesterol emboli proximal and distal to the aneurysm, and another had a branch arterial occlusion.

Our observations on Case I suggest that arterial aneurysms may develop as a result of focal damage to the vascular wall. The patient presented with a bright intraluminal plaque and angiographic evidence of an incomplete arterial occlusion. The plaque was probably embolic in origin, although thrombosis from local vessel disease cannot be excluded. Subsequently she developed aneurysms both at the site of the plaque, at the next proximal bifurcation of the artery, and along its dichotomous branch in which an intraluri.al plaque had also been seen. We believe that an injury to the vessel wall could allow loss of its functional continuity and lead to the formation of an aneurysm. The fact that most aneurysms form at arterial bifurcations or at arterio-venous crossings may imply either more common sites of embolic impact or zones of intrinsic vascular weakness. Similarly, the observation of intra-arterial plaques in six of 16 affected eyes and the history and objective findings of vascular occlusions in nine patients further suggests a setting for vessel damage. One can speculate about the role of hypertension in predisposing or fomenting aneurysms after such internal injury. Certainly the high incidence of documented systemic hypertension and hypertensive vascular changes in both affected and fellow eyes cannot be ignored.

With the enhancement of fluorescein angiography, intraretinal microvascular abnormalities in the vicinity of aneurysm were recorded in about one-half of the aneurysms. These alterations included local widening of the periarterial or perianeurysmal capillary-free zone, dilatation of the adjacent capillary bed with small zones of capillary non-perfusion, capillary microaneurysms rimming the avascular zone around the aneurysm, and fine intra-arterial collateral formation. In several patients we observed the evolution of these microvascular changes. Robertson comments on 'abnormal dilatation or neovascularization within the area of serous fluid surrounding the macroaneurysm' in two of his patients, in one of whom the anomaly was apparently present before the development of the aneurysm. He speculated that chronic venous obstruction might influence their origin. Alternatively, these microvascular changes resemble the reorganization of small vessel networks which have been shown in experimental embolic arterial occlusions by Dollery, Henkind, Paterson, Ramalho, and Hill (1966), Henkind (1966), and Klein, Klein, Henkind, and Bellhorn (I97I). It is conceivable that our observations represent a similar compensation of local blood flow, caused by either previous embolic matter or mechanical forces in the damaged or expanding arterial wall.

The visual complication of acquired retinal artery aneurysms most commonly responsible for the patients' complaints is macular oedema with circinate retinopathy. Two patients in our series presented with vitreous haemorrhage. Local intraretinal haemorrhage at the site of the aneurysm was noted in one-half of the affected eyes during the period of observation but implied no predictive value of visual function or course. In all cases of macular oedema and other aneurysms with local oedema and fatty exudate, fluorescein angiography demonstrated staining of the aneurysmal wall, suggesting defective integrity of the endothelium permitting dye leakage into the surrounding retina. Fluorescein also leaked from zones of microvascular abnormalities.

Among the $\mathrm{I} 6$ eyes comprising this survey, five eyes were followed without therapy, and one patient was lost to ophthalmic observation after discovery of her lesion (Case 2). Three of the five patients observed without therapy had good and stable visual acuity in the affected eye for up to 5 years after presentation. One patient spontaneously improved from $20 / 400$ to $20 / 30$ acuity in the 3 months before consultation and remained at that level for 16 months. The fifth patient had chronic bilateral uveitis, vitritis, and cystoid macular oedema, and $20 / 50$ vision in each eye. Because the macroaneurysm did not appear to contribute significantly to the macular oedema, photocoagulation was not considered. Six months later the visual acuity was unchanged in each eye. All untreated aneurysms remained patent during the follow-up period.

Five eyes were treated with xenon arc photocoagulation. Although most of these patients were followed-up from 6 weeks to 7 months before treatment, the level of visual recovery was judged to be 
unsatisfactory. Treatment resulted in visual improvement of two or more lines of a Snellen chart in three of five eyes. One patient (Case II) who had presented with vitreous haemorrhage and had evidence of an epiretinal membrane with macular traction from the aneurysm before treatment, was lost to follow-up 7 weeks after therapy with an unchanged visual acuity of 20/100. Another patient (Case 6) presented with a dense senile cataract and developed a cellophane membrane in the macula after treatment.

Of five eyes treated with argon laser photocoagution, three showed improvement of two lines or more of Snellen acuity. One other patient developed a branch arterial occlusion distal to the area of treatment and pretreatment visual acuity of $20 / 200$ was unchanged nearly 3 years later. The other patient had a history of paracentral chorio-retinitis and retinal vascular occlusions. The visual acuity remained unchanged at 20/200 5 months after treatment.

All treated aneurysms were obliterated both ophthalmoscopically and angiographically. Visual improvement was documented as early as 3 days and on average 6 to 8 weeks after photocoagulation. Our experience suggests that photocoagulation may speed visual improvement in patients with macular oedema and circinate retinopathy who have not improved spontaneously after 3 months of observation. Photocoagulation is probably indicated if the aneurysm increases in size and if further exudation results in failing visual acuity (Gass, 1972). However, additional experience with photocoagulation is required to confirm these impressions. Macroaneurysms not affecting macular function probably do not need photocoagulation.

\section{Summary}

Fifteen patients with acquired arterial macroaneurysms of the retina, and an additional woman patient with some 18 aneurysms of the temporal retinal arterial tree of one eye, are described. Acquired aneurysms occur in patients in their sixth decade and older, are usually unilateral, and occur on the major arterial branches posterior to the equator. Customarily only one or two aneurysms are present. Most patients have a history of poorly controlled systemic hypertension or a raised blood pressure at the time of discovery of the macroaneurysm. Focal embolic damage to arterial walls should be considered in the investigation of these patients. In patients with decreased vision from macular oedema and circinate retinopathy, photocoagulation of the macroaneurysm may hasten the improvement in visual acuity.

We thank Victor T. Curtin, MD, and James C. Major, $\mathrm{MD}$, for permission to report the findings in their patients. We also thank William L. Hutton, MD, who generated our initial interest in this subject.

Three of these cases were presented in part at the International Fluorescein Conference, Tokyo, Japan, on I-6 February 1972.

The medical history of Case 2 was previously reported in part by Burr, Farrell, and Hills (1959).

\section{References}

ARCHER, D., and KRILL, A. E. (197I) Surv. Ophthal., 15, 384 ASHTON, N., and LANGLEy, D. (I95I) Brit. F. Ophthal., 35, 424 Ballantyne, A. J. (1937) Trans. ophthal. Soc. U.K., 57, 301

BURR, J. M., FARRELL, J. J., and Hills, A. G. (1959) New Engl. F. Med., 26r, 127 I DOllery, C. T., HeNkind, P., PATERSON, J. W., RAMAlHo, P. S., and hill, D. w. (1966) Brit. F. Ophthal., 50, 285 DOYNE, R. W. (1896) Trans. ophthal. Soc. U.K., 16, 94 EGERER, I., TASMAN, W., and TOMER, T. L. (1974) Arch. Ophthal., 92, I09 FERNANDEZ, F. M. (1920) Amer. F. Ophthal., 3, 64I

GASS, J. D. M. (1972) Trans. ophthal. Soc. U.K., 92, 449

HENKIND, P. (1966) Brit. F. Ophthal., 50, 482

HUDOMEL, J., and IMRE, G. (1973) Acta ophthal. (Kbh.), 5r, 633

KLEIN, R., KLEIN, B., HENKIND, P., and BELlHORN, R. (1971) Invest. Ophthal., Io, 47 I

LEWIS, R. A., COHEN, M. H., and WISE, G. N. (1975) Brit. F. Ophthal., 59, 422

raehlmann, E. (1902) Z. Augenheilk., 7, 425

robertson, D. M. (1973) Trans. Amer. Acad. Ophthal. Otolaryng., 77, 55

Shults, w. T., and swan, к. c. (1974) Amer. F. Ophthal., 77, 304

STORY, J. B., and Benson, A. H. (1883) Trans. ophthal. Soc. U.K., 3, 108

WALSH, F. B., and HOYT, W. F. (1969) In 'Clinical Neuro-Ophthalmology', 3rd ed, vol. 2, p. 1737. Williams \&

Wilkins, Baltimore 